\title{
Media Content Analysis of Marijuana's Health Effects in News Coverage
}

\author{
Ann Abraham, $B S^{7}$, Alysandra J. Zhang, $B A^{7}$, Rosa Ahn, $B A^{2}$, Alexandra Woodbridge, $B S, B A^{3}$, \\ Deborah Korenstein, $\mathrm{MD}^{4}$, and Salomeh Keyhani, $M D, M P H^{1.5}$
}

${ }^{1}$ San Francisco VA Medical Center, San Francisco, CA, USA; ${ }^{2}$ Oregon Health and Science University, Portland, OR, USA; ${ }^{3}$ Tulane University School of Medicine, New Orleans, LA, USA; ${ }^{4}$ Memorial Sloan Kettering Cancer Center, New York, NY, USA; ${ }^{5}$ Department of General Internal Medicine,

University of California, San Francisco, San Francisco, CA, USA.

J Gen Intern Med 33(9): 1438-40

DOI: $10.1007 / \mathrm{s} 11606-018-4492-9$

(c) Society of General Internal Medicine (This is a U.S. Government work and not under copyright protection in the US; foreign copyright protection may apply) 2018

\section{INTRODUCTION}

The prevalence of marijuana use has doubled in the past decade. One in eight US adults now reports use of marijuana in the past year. ${ }^{1}$ Despite increasing use, our understanding of the risks and benefits of marijuana use is limited. ${ }^{1-3}$ The National Academy of Sciences, editorials, and numerous systematic reviews have called for more research. ${ }^{1-3}$ Despite concerns within the scientific community, only $33 \%$ of the public perceive "great risk" from weekly marijuana use compared to $50 \%$ in $2002 .{ }^{1}$ The public appears to believe that recreational marijuana use is safe and even has health benefits. $^{1}$

The media contributes greatly to the national perspective on health ${ }^{4}$ but may provide incomplete information. ${ }^{4}$ We examined a cross-section of news media coverage to better understand how the media may influence the public's view of marijuana.

\section{METHODS}

We identified the top 10 major news outlets by print circulation using Pew's 2014 ranking. ${ }^{5}$ We selected those with articles available on LexisNexis, including The New York Times, The Daily News New York, The New York Post, The Denver Post, USA Today, and the Los Angeles Times; these have a combined total of approximately 4.9 million daily visitors.

We selected articles published between 1/1/12 (Colorado's recreational legalization) and 5/1/2016 (the study's initiation date), with major subject "marijuana." If more than 100 articles were available from any publication, 100 were randomly selected. We excluded articles $<100$ words, editorials, and those without a marijuana focus. One reviewer (AW or RA) categorized each article by focus health, business, public

Ann Abraham and Alysandra J. Zhang contributed to work equally and are considered co-first authors.

Published online May 29, 2018 policy, crime, and entertainment/other and flagged them for health mentions. Each article with a mention was abstracted independently by two reviewers (AZ, RA) for overall message content. Overall content was categorized as follows: (1) marijuana benefits outweigh harms, (2) marijuana harms outweigh benefits, or (3) neutral impression of harms vs. benefits. Disagreements were adjudicated by a third abstractor (AA). We analyzed the relationship between the article's overall slant and other characteristics using descriptive statistics.

Data Availability. Dataset available from corresponding author on request.

\section{RESULTS}

We identified 564 articles of which 477 met inclusion criteria. Articles' focus were categorized as public policy $(n=190$, $39.8 \%)$, crime ( $n=113,23.7 \%)$, business $(n=74,15.5 \%)$, entertainment/other $(n=69,14.5 \%)$, and health $(n=31$, $6.5 \%)$. Health mentions were found in a third of articles $(n=$ $145,30.4 \%)$, of which $89(61.3 \%)$ mentioned health benefits, and $98(67.5 \%)$ mentioned harms (Table 1). About half of articles with health mentions $(n=72,49.7 \%)$ communicated a favorable impression of marijuana (net benefit), 46 (31.7\%) communicated a negative impression (net harm), and 27 (18.6\%) were neutral. Articles that were not focused on health were more likely to communicate a favorable impression of marijuana $(p<.001)$. Of the 31 articles that were focused on health and public health, 13 (41.9\%) acknowledged weaknesses in the evidence base surrounding marijuana while 18 (58.1\%) did not. Articles discussing both benefits and harms were more likely to communicate a favorable impression of marijuana $(p<.001)$. The proportion of articles with favorable mentions of marijuana increased from $11.1 \%$ in 2012 to $65 \%$ in 2016 .

\section{DISCUSSION}

Most articles on marijuana do not mention health effects. Nearly half of articles in our sample that mentioned health 
Table 1 Characteristics of Articles That Mentioned Health Effects

\begin{tabular}{|c|c|c|c|c|c|}
\hline & $\begin{array}{l}\text { Positive impression (benefits } \\
\text { outweigh harms) }(N=72)\end{array}$ & $\begin{array}{l}\text { Negative impression (harms } \\
\text { outweigh benefits) }(N=46)\end{array}$ & $\begin{array}{l}\text { Neutral impression } \\
(N=27)\end{array}$ & Total & $\overline{p \text { value }}$ \\
\hline \multicolumn{6}{|l|}{ Article focus } \\
\hline Health and public health & $6(19.4)$ & $21(67.7)$ & $4(12.9)$ & 31 & $<.001$ \\
\hline Non-health* & $66(57.9)$ & 25 (21.9) & $23(20.2)$ & 114 & \\
\hline Total & $72(49.7)$ & $46(31.7)$ & $27(18.6)$ & 145 & \\
\hline \multicolumn{6}{|l|}{ Publication } \\
\hline USA Today & $11(33.3)$ & $16(48.5)$ & $6(18.2)$ & 33 & $<.001$ \\
\hline New York Times & $13(39.4)$ & $11(33.3)$ & $9(27.3)$ & 33 & \\
\hline Los Angeles Times ${ }^{\dagger}$ & $21(77.8)$ & $2(7.4)$ & $4(14.8)$ & & \\
\hline New York Post & $9(60.0)$ & $4(26.7)$ & $2(13.3)$ & 15 & \\
\hline The Denver Post & $5(26.3)$ & $9(47.4)$ & $5(26.3)$ & & \\
\hline Daily News New York & $13(72.2)$ & $4(22.2)$ & $1(5.6)$ & 18 & \\
\hline \multicolumn{6}{|l|}{ Health effects listed in article } \\
\hline Described both benefits and harms & $24(54.5)$ & $9(20.5)$ & $11(25.0)$ & 44 & $<.001$ \\
\hline Described benefits only & $42(93.3)$ & $0(0)$ & $3(6.7)$ & 45 & \\
\hline Described harms only & $5(9.3)$ & $37(68.5)$ & $12(22.2)$ & 54 & \\
\hline \multicolumn{6}{|l|}{ Year of publication } \\
\hline 2012 & $1(11.1)$ & $6(66.7)$ & $2(22.2)$ & 9 & 0.10 \\
\hline 2013 & $8(36.4)$ & $8(36.4)$ & $6(27.3)$ & 22 & \\
\hline 2014 & $28(48.3)$ & $21(36.2)$ & $9(15.5)$ & 58 & \\
\hline 2015 & $22(61.1)$ & $7(19.4)$ & $7(19.4)$ & 36 & \\
\hline 2016 & $13(65.0)$ & $4(20.0)$ & $3(15.0)$ & 20 & \\
\hline
\end{tabular}

*Articles related to business, public policy, celebrity/entertainment/other, crime

${ }^{*}$ Only the past 6 months were available on LexisNexis

${ }^{*}$ Two articles while focused on health did not mention explicit benefits or harms and were therefore not included in this analysis

effects communicated a favorable impression of marijuana. Articles that focused exclusively on health-related issues of marijuana were more likely to communicate a nuanced view on marijuana use; however, these articles represented a small portion of all marijuana articles $(6.5 \%, 31 / 477)$. Articles covering public policy and business aspects of recreational legalization tended to communicate more benefits than harms. Given that many reported therapeutic benefits have insufficient evidence, ${ }^{2,3}$ the media's coverage slant is concerning and may lead the public to underestimate health risks associated with frequent marijuana use. ${ }^{1,6}$

Our study has limitations that deserve comment. Top print circulation newspapers are dominated by coastal outlets whose favorable messaging may not be generalizable. On the other hand, the newspapers included have an outsized influence on public discourse. In addition, print has declined in relation to digital media. However, while our sampling strategy relied on print articles, these articles are also available in digital format on news websites and widely shared in social media.

In conclusion, major news outlets communicate a more positive message regarding marijuana use than is warranted by current evidence. A concerted public health response is needed to counter the inaccurate information provided to the public.

Corresponding Author: Salomeh Keyhani, MD, MPH; Department of General Internal Medicine University of California, San Francisco, San Francisco, CA, USA (e-mail: Salomeh.keyhani@ucsf.edu).

Contributors $S K$ had the idea for the study. SK, DK, AA, RA, AW, and $A Z$ created the study design. $A A, R A, A W$, and $A Z$ collected the data. SK and DK verified the data. SK, RA, AW, AA, AZ, and DK analyzed and interpreted the data. $A A, A Z, R A, A W, S K$, and $D K$ wrote and revised the manuscript. All authors critically revised the manuscript and approved the final version for submission. $A A$ and $A Z$ contributed equally to the work and are considered co-first authors. SK is the guarantor.

Funding This project was not directly supported by any research funds. Dr. Keyhani is funded by grants from the NIH grants (ROI HL116522-01A1, RO1 HL114563-O1A1) and VA HSR\&D (1IP1HX001994). Dr. Korenstein's work on this paper was supported by a Cancer Center Support Grant from the National Cancer Institute to Memorial Sloan Kettering Cancer Center (award number P3O CA008748).

\section{Compliance with Ethical Standards:}

Conflict of Interest: The authors declare that they do not have a conflict of interest.

\section{Ethical Approval: Not needed}

Transparency: The manuscript's guarantor (SK) affirms that this manuscript is an honest, accurate, and transparent account of the study being reported; that no important aspects of the study have been omitted; and that any discrepancies from the study as planned have been explained.

\section{REFERENCES}

1. Compton WM, Han B, Jones CM, Blanco C, Hughes A. Marijuana use and use disorders in adults in the USA, 2002-14: analysis of annual crosssectional surveys. Lancet Psychiatry. 2016;3(10):954-964. https://doi. org/10.1016/s2215-0366(16)30208-5.

2. National Academies of Sciences, Engineering, and Medicine. 2017. The Health Effects of Cannabis and Cannabinoids: Current State of Evidence and Recommendations for Research. Washington, DC: The National Academies Press.

3. Nugent SM, Morasco BJ, O'Neil ME, Freeman M, Low A, Kondo K, et al. The effects of cannabis among adults with chronic pain and an overview of general harms: a systematic review. Ann Intern Med. 2017;167:319-331. https://doi.org/10.7326/M17-0155 
4. Dumas-Mallet E, Smith A, Boraud T, Gonon F. Poor replication validity of biomedical association studies reported by newspapers. Plos One. 2017;12(2). https://doi.org/10.1371/journal.pone.0172650.

5. Pew Research Center, "State of the News Media 2014: Overview" http:// assets.pewresearch.org/wp-content/uploads/sites/13/2017/05/ 30142556/state-of-the-news-media-report-2014-final.pdf. Published March, 2014. Accessed April 18, 2018.

6. Barry RA, Glantz S. A public health framework for legalized retail marijuana based on the US experience: avoiding a new tobacco industry. PLOS Med. 2016;13(9). https://doi.org/10.1371/journal.pmed.1002131. 